\title{
Effect of Xenon Arc Lamp Irradiation on Properties of Polymethyl Methacrylate for Aviation
}

\author{
Jiangyan Meng, Yunying Wang \\ Key Laboratory of Nondestructive Testing, Nanchang Hangkong University, Ministry of Education, Nanchang, \\ China \\ Email: mengjiangyan_sci@163.com, yywang4321@126.com
}

Received 1 December 2014; accepted 15 December 2014; published 14 January 2015

Copyright (C) 2015 by authors and Scientific Research Publishing Inc.

This work is licensed under the Creative Commons Attribution International License (CC BY). http://creativecommons.org/licenses/by/4.0/

cC) (i) Open Access

\begin{abstract}
YB-2 aviation polymethyl methacrylate (PMMA) is irradiated in a xenon arc lamp weather resistance test chamber for 1620 hours. The tensile strength, light transmittance, surface morphology, relative molecular mass, infrared absorption spectrum and glass transition temperature $\left(T_{g}\right)$ of PMMA exposed in xenon arc lamp for different durations are tested and characterized by universal testing machine, optical haze instrument, scanning electronic microscopy (SEM), gel permeation chromatograph (GPC), fourier transform infrared spectrometer (FT-IR) and differential scanning calorimetry (DSC), so as to comprehensively analyze the influence of xenon arc lamp irradiation on the performance of PMMA. The results reveal that under the effect of 1620 hours xenon arc lamp irradiation and periodic spraying water, the light transmittance and glass transition temperature do not change significantly, and no new chemical group is produced. After irradiated 360 hours, tiny cracks occur in the surface of PMMA, indicating that they occur at a certain degree of degradation, meanwhile, the main chain may be broken and the relative molecular mass of surface of the material decreases. After exposure of 720 hours, the tensile strength decreases about $30 \%$.
\end{abstract}

\section{Keywords}

Aviation Perspex, Xenon Arc lamp Irradiation, Relative Molecular Mass, Surface Morphology, Gel Permeation Chromatograph

\section{Introduction}

To guarantee the normal flight and air safety of aircrafts, aviation perspex components such as windshields or canopies must have excellent optical performance, sufficient toughness and long service life. However, for po- 
lymer materials such as aviation perspex, exposure to light, hot and humidity conditions is easy to result in color change, transmittance decrease and mechanical performance reduction [1] [2]. Therefore, it is of great importance to investigate the effect of environmental factors on the properties of aviation perspex. Researchers around the world have investigated the performance evolution discipline and mechanism of aviation perspex under different environments, by simulating environmental parameters such as atmosphere, thermal oxidation, humidity and ultraviolet (UV). They conclude that sunlight is the main factor which leads to the performance change of PMMA [3]-[8].

Xenon arc lamp accelerated aging, which is capable to simulate environment with sunlight and humidity-heat, is a kind of accelerated test method suitable to simulate the weather resistance of polymer materials. Due to its relatively high cost, there are few reports concerning the performance change of aviation perspex under xenon arc lamp irradiation both at home and abroad. Therefore, in this research, xenon arc lamp irradiation test of aviation perspex for 1620 hours is carried out to observe, characterize and test the morphology, structure and performance of PMMA, so as to discuss the behaviors of aviation perspex during exposure to xenon arc lamp irradiation.

\section{Experimental}

\subsection{Xenon Arc Lamp Irradiation of the Sample}

According to GB/T 16422.2-1999, YB-2 aviation perspex with thickness of $2 \mathrm{~mm}$ is placed in an SN-500 xenon weather-ometer. The blackboard temperature is set as $50^{\circ} \mathrm{C} \pm 3{ }^{\circ} \mathrm{C}$, and the spray interval is set as 102 minutes with each spray lasting for 18 minutes. The sampling period is 180 hours (15 days), and the accumulative irradiation time is 1620 hours.

\subsection{Characterization and Testing}

- Gaseous phase gel permeation chromatograph (GPC). The relative molecular mass of PMMA after exposure to xenon arc lamp irradiation for different durations is characterized by Water 515 gel permeation chromatograph (GPC).

- Fourier transforms infrared absorption spectrum (FT-IR). The infrared absorption spectrum of PMMA after exposure to xenon arc lamp irradiation for different durations is characterized using VERTEX 720 infrared spectrometer.

- Characterization of glass transition temperature $\left(T_{g}\right)$. The aviation perspex after irradiated by xenon arc lamp for different durations is tested using a DSC 6200 differential scanning calorimeter. DSC curves are obtained with temperature increasing from $20^{\circ} \mathrm{C}$ to $200^{\circ} \mathrm{C}$ at a rate of $10^{\circ} \mathrm{C} / \mathrm{min}$, and the midpoint temperature is selected as the glass transition temperature according to GB/T 19466.2-2004.

- Light transmittance. The light transmittance of PMMA after exposure to xenon arc lamp irradiation for different durations is characterized using WGW optical haze instrument.

- Surface morphology. The surface morphology of PMMA after exposure to xenon arc lamp irradiation for different durations is observed using DM 1500 optical microscope and Quanta 200 scanning microscope.

- Tensile strength. According to GB/T 1040-1992, the tensile strength of PMMA after exposure to xenon arc lamp irradiation for different durations is tested by WDX-50C universal testing machine using II-type specimens, with jig separation speed $2 \mathrm{~mm} / \mathrm{min}$.

\section{Results and Discussions}

\subsection{Surface Morphology of PMMA}

The surface morphologies of PMMA samples after exposure to xenon arc lamp for different durations are shown as Figure 1(a). As shown in Figure 1(a), before exposure to xenon arc lamp, the surface of sample is smooth without any damage. As shown in Figure 1(c), after irradiated by xenon arc lamp for 900 hours, damages occur and do not get worse even after 1620 hours, but cracks begin to arise. Figure 1(d) is an enlarged view of cracks, in which the cracks are smooth with flat surfaces nearby. It is supposed that cracking caused by the internal stress [9] [10]. 


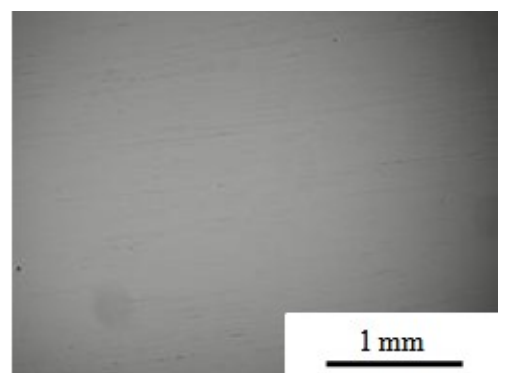

(a)

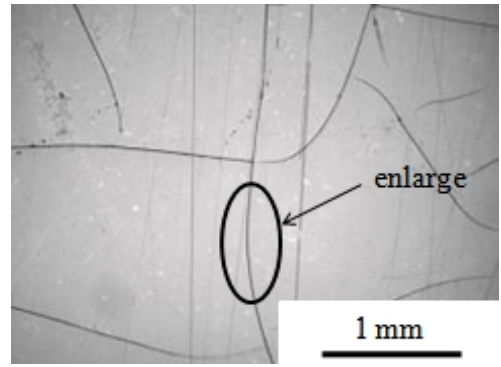

(c)

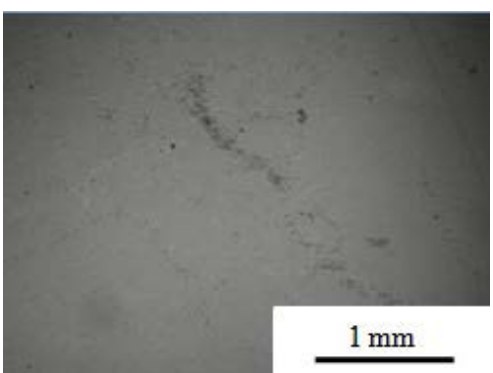

(b)

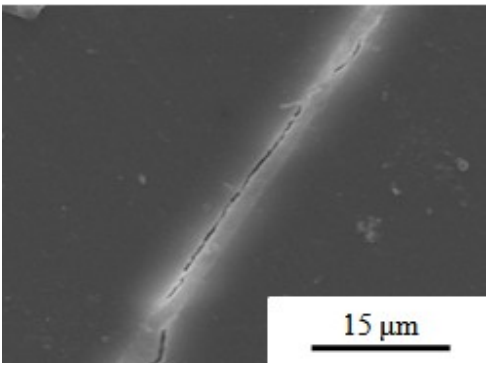

(d)

Figure 1. Morphology of aviation perspex under different xenon irradiation time: (a) 0 hour (non-aged); (b) 900 hours; (c) 1620 hours; (d) 1620 hours (circle of Figure 3(c)).

During spraying in the irradiation process, water will lead to the sudden drop of temperature in the surface of the sample. And when the spraying stops, the temperature will return to the blackboard temperature. Long-term of changing between cold and hot will result in internal stress in the materials, which will lead to cracks in the surface.

\subsection{Infrared Absorption Spectrum and Related Analysis of PMMA}

The photodegradation reaction of PMMA mainly includes the degradation of lateral ester group and methyl side group, and the random degradation of main chain. The groups in the photodegradation products mainly include O-H $\left(3441 \mathrm{~cm}^{-1}\right), \mathrm{C}-\mathrm{H}\left(2977 \mathrm{~cm}^{-1}, 2953 \mathrm{~cm}^{-1}\right), \mathrm{C}=\mathrm{O}\left(1730 \mathrm{~cm}^{-1}\right), \mathrm{C}=\mathrm{C}\left(1632 \mathrm{~cm}^{-1}\right)$ and $\mathrm{C}-\mathrm{O}\left(1148 \mathrm{~cm}^{-1}\right)$, which are the same with those in the perspex molecular chain before degradation. There isn't any new absorption peak in the infrared absorption spectrum of PMMA after degradation, either the change of peak's wavenumber.

The infrared absorption spectrum of PMMA before and after the irradiation is shown as Figure 2. The positions of characteristic absorption peaks in the infrared absorption spectrum do not change after exposure to xenon arc lamp and no new characteristic absorption peak occurs. Therefore, it is indicated that no new group is produced in the main chain after irradiated. Testing results in Figure 2 agree well with the conclusions drawn in [11].

\subsection{Comprehensive Temperature Analysis}

The DSC of PMMA after exposure to xenon arc lamp for different durations is displayed in Figure 3. According to GB/T 19466.2-2004, the glass transition temperature of PMMA can be determined, as listed in Table 1. Based on Figure 3 and Table 1, we can learn that the DSC curves of aviation perspex after exposure to xenon arc lamp for different durations are similar with each other, i.e., after irradiated by xenon arc lamp for 900 hours and 1620 hours respectively, the glass transition temperature keeps about same value.

Usually, changes in the relative molecular mass of polymers will result in the change of their glass transition temperatures. According to the GPC results, xenon arc lamp irradiation will lead to the decrease of the relative molecular mass of PMMA. Even though it experiences a decrease of about $19.5 \%$, it still keeps an absolute value of $6.2 \times 10^{5}$. Therefore, even after exposure to xenon arc lamp for 1620 hours, there is still no significant change in its glass transition temperature. 


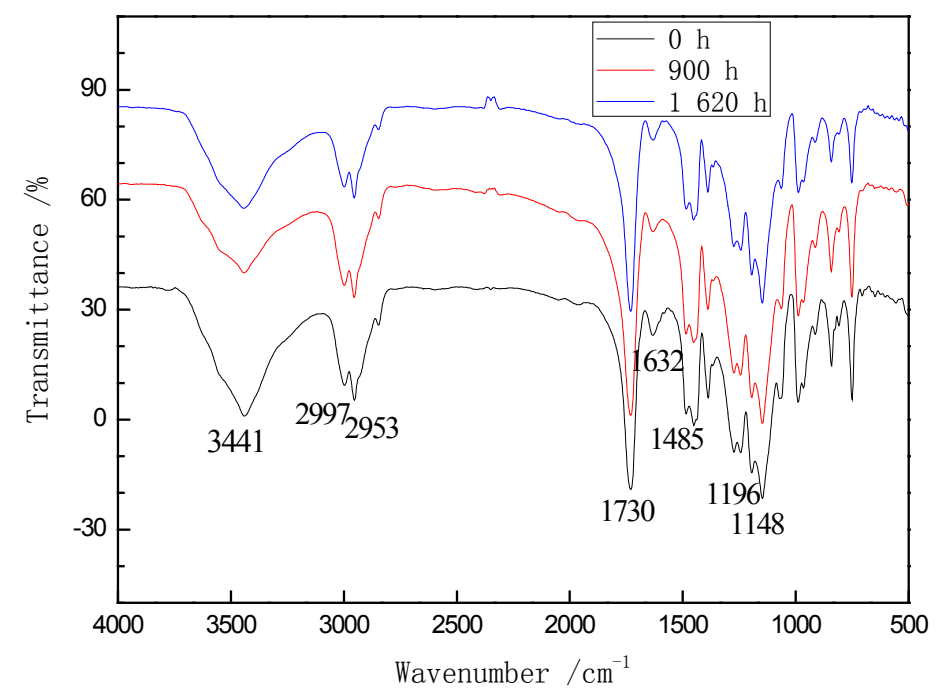

Figure 2. Infrared spectrometry of aviation perspex under different xenon irradiation time.

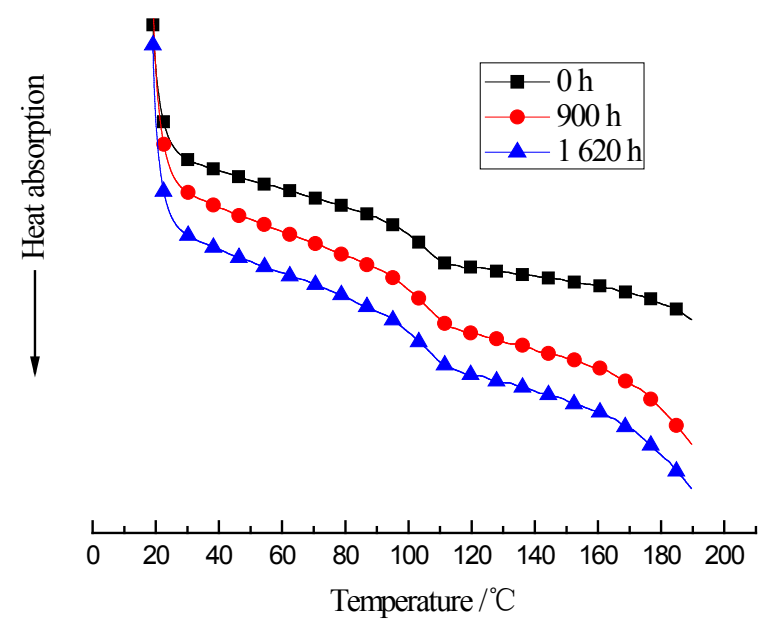

Figure 3. DSC of aviation perspex under different xenon irradiation time.

Table 1. $T_{g}$ of aviation perspex under different xenon irradiation time.

\begin{tabular}{cccc}
\hline Irradiation time $/ \mathrm{h}$ & 0 & 900 & 1620 \\
\hline$T_{g}{ }^{\circ} \mathrm{C}$ & 104.3 & 105.4 & 105.7 \\
\hline
\end{tabular}

\subsection{Transparence Analysis}

Light transmittance of aviation perspex after xenon arc lamp irradiation is shown in Figure 4. As it is displayed, the transparence changes very little, indicating that the xenon arc lamp irradiation has very limited influence on the transmittance of aviation perspex. After exposure to xenon arc lamp for $1620 \mathrm{~h}$, the light transmittance decreases by $1 \%$, but still above $91 \%$.

The transmittance of aviation perspex is determined by the deflection, absorption and scattering of light ray, which is essentially decided by its structure. When light goes through, the less loss of light, the higher is the transmittance. The change of transmittance directly reflects the change scope of chain structure and aggregation structure in PMMA. After xenon arc lamp irradiation, degradation only occurs in the surface of aviation perspex and its molecular mass still remains at $6.2 \times 10^{5}$. Generally, there is nearly no change in the chain structure and aggregation structure of perspex and consequently no change in the optical performance. 


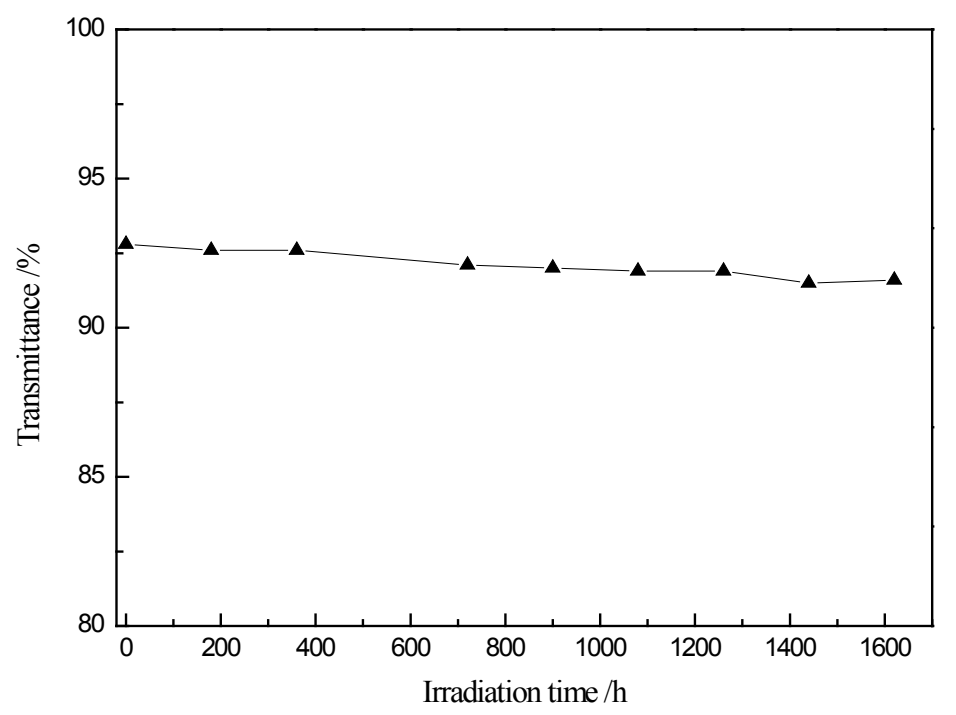

Figure 4. Evolution of transmittance with xenon irradiation time for PMMA.

\subsection{Relative Molecular Mass in the Surface of PMMA}

GPC curves of aviation perspex after exposure to xenon arc lamp for different durations is shown as Figure 5. According to Figure 5, the relative molecular mass of PMMA decreases, indicating that xenon arc lamp irradiation will lead to the main chain broken in PMMA [12]. After exposure to xenon arc lampfor $360 \mathrm{~h}$, the relative molecular mass begins to decrease, and the number-average molecular mass $(\mathrm{Mn})$ decreases to $6.2 \times 10^{5}$ from $7.7 \times 10^{5}$ with a lowering extent of $19.48 \%$. Along with the increase of exposure time, Mn remains at about 6.2 $\times 10^{5}$ without a further decrease, which reveals that the degradation degree of aviation perspex doesn't continue to increase.

\subsection{Tensile Strength}

Figure 6 displays the change of tensile strength of aviation perspex after exposure to xenon arc lampfor different durations. As shown in the figure, at the initial stage of xenon arc lamp irradiation (before $720 \mathrm{~h}$ ), there is no obvious change in the tensile strength, but with irradiation going on, the tensile strength decreases gradually. After irradiated for $1620 \mathrm{~h}$, the tensile strength decreases to $30.45 \mathrm{MPa}$ from the initial $45 \mathrm{MPa}$, with a decrease extent of $33 \%$.

According to the surface morphology, the degradation of aviation perspex mainly happens in the surface with a relative low degradation degree, which has little influence on the tensile strength. Therefore the tensile strength changes little at the initial irradiation process. With irradiation going on, stress cracking starts to occur in the surface. The tensile stress transmits along the crack direction under tensile stress and cracks become expanded and enlarged [13], resulting in the facture of aviation perspex specimens even at relative low tensile stress, i.e. the decrease of tensile strength.

\section{Conclusions}

- Short-term irradiation of xenon arc lamp has little influence on the structure and performance of aviation perspex. After exposure to xenon arc lamp irradiation for $720 \mathrm{~h}$, the tensile strength gradually decreases with time going on.

- Xenon arc lamp irradiation leads to a certain extent of degradation in the aviation perspex, with a decreased relative molecular mass, but no new group is produced.

- After exposure to xenon arc lamp for 1620 hours, the light transmittance of aviation perspex does not experience an obvious decrease (less than 1\%), indicating that xenon arc lamp irradiation has little influence on its optical performance. Meanwhile, there is no notable decrease in the glass transition temperature, revealing that aviation perspex has perfect thermo-stability. 


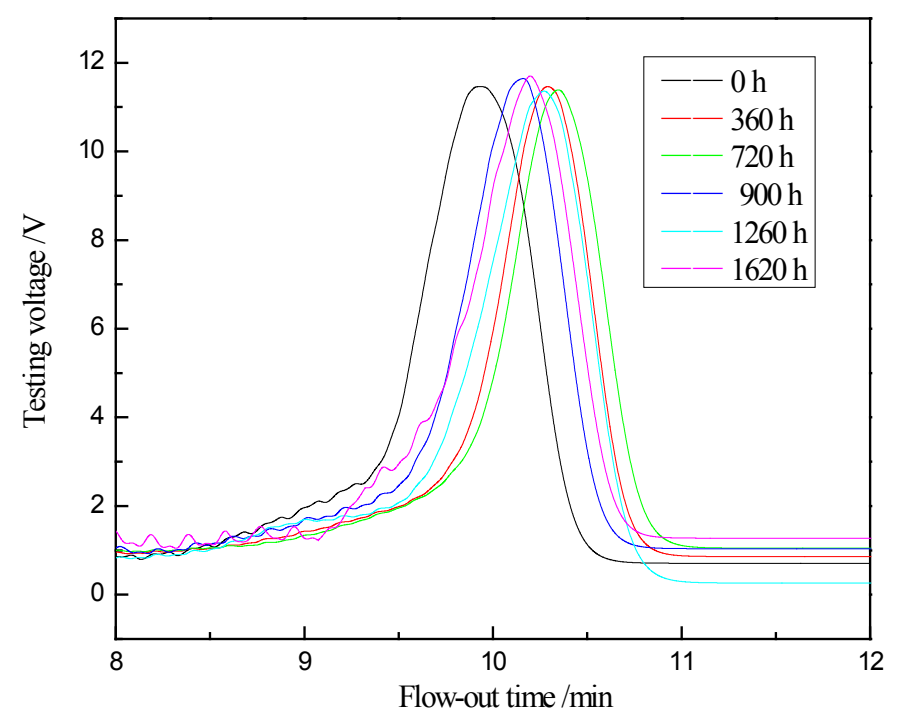

Figure 5. GPC of aviation perspex under different xenon irradiation time.

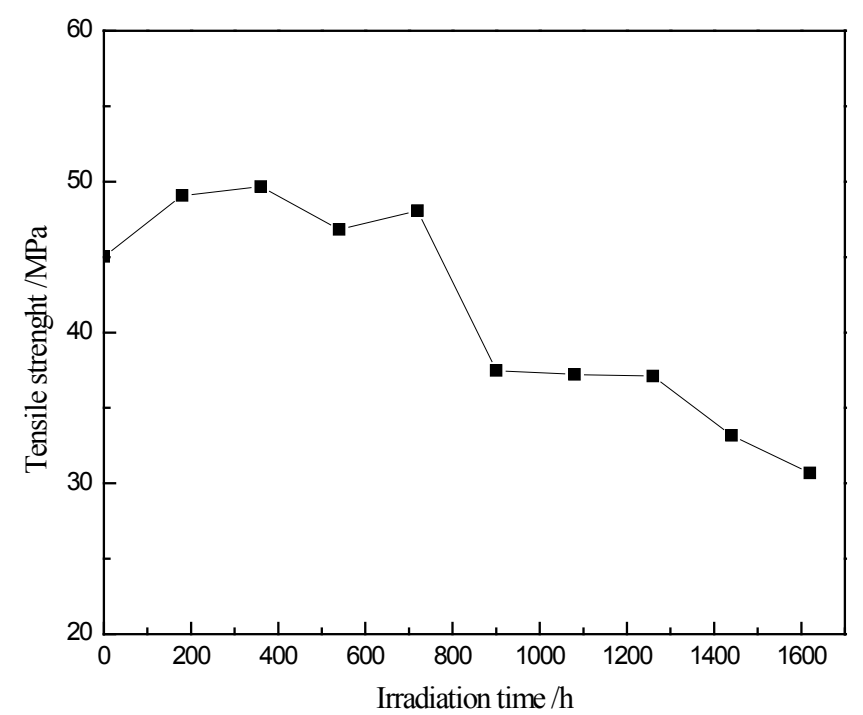

Figure 6. Evolution of tensile strength with xenon irradiation time for aviation perspex.

- Under the synergistic effect of long-term xenon arc lamp irradiation and hygrothermal environment, internal stress of aviation perspex was occurred, leading to the relative obvious stress cracking in the surface, which is the typical characteristic of aging.

\section{Acknowledgements}

This work was supported by the Aeronautics Science Foundation (20120956005).

\section{References}

[1] Chinese Aviation Materials Manual Editorial Board (2002) Chinese Aviation Materials Manual, Plastics Transparent materials Insulating Materials. Vol. 7, China Standards Press, Beijing, 223.

[2] Li, X.G., Gao, J., Zhang, S.P., et al. (2011) The Aging Principle and Mechanism of High Polymer Material in Natural Environment. Science Press, Beijing, 7-8, 21-104.

[3] Liu, H.Y., Li, X.M. and Wang, H.B. (2011) Research on Accelerated Weathering Test Technique of Perspex. Equip- 
ment Environmental Engineering, 8, 83-86.

[4] Chang, T.C., Yu, P.Y., Hong, Y.S., et al. (2002) Effect of Phenolic Phosphate Antioxidant on the Thermo-Oxidative Degradation of PMMA. Polymer Degradation \& Stablization, 77, 29-34. http://dx.doi.org/10.1016/S0141-3910(02)00076-9

[5] Darowicki, K., Szocinski, M., Schaefer, K., et al. (2011) Investigation of Morphological and Electrical Properties of the PMMA Coating upon Exposure to UV Irradiation based on AFM Studies. Progress in Organic Coatings, 71, 65-71. http://dx.doi.org/10.1016/j.porgcoat.2010.12.012

[6] Motaung, T.E., Luyt, A.S., Bondioli, F., et al. (2012) PMMA-Titania Nanocomposites: Properties and Thermal Degradation Behavior. Polymer Degradation \& Stablization, 97, 1325-1333. http://dx.doi.org/10.1016/j.polymdegradstab.2012.05.022

[7] Hou, Y.L., Qiao, Q.J. and Li, H.C. (2006) An Equivalent Relationship of the Perspex Fatigue Life between the Natural and Artificial Aging. Journal of Henan University (Natural Science), 36,118-122.

[8] Ma, L.T., Chen, X.W. and Su, B. (2008) Aging Mechanism of Perspex under the Typical Environment. Physical Testing and Chemical Analysis Part A: Physical Testing, 44, 64-67.

[9] He, M.J., Zhang, H.D., Chen, X.W., et al. (2008) High Polymer Physics. Fudan University Press, Shanghai, 114-122, 206-208.

[10] Zhang, L.Y. (1999) The Progress and Application of Transparent Polymer Materials. New Chemical Materials, 27, 37-40.

[11] Zhong, S.Y., Xu, Q.W. and Wang, G.S. (2002) Polymer Degradation and Stabilization. Chemical Industry Press, Beijing, 94-96.

[12] Zhu, Q.Q. and Feng, L.X. (1995) Optically Transparent Macromolecule Materials. Polymer Material Science and Engineering, 11, 1-6.

[13] Chen, X.W., Zhang, T.J. and Liu, S.H. (2009) Accelerated Ageing Behavior of PMMA under Hygrothermal Air and Water Conditions. Failure Analysis and Prevention, 4, 193-195. 
Scientific Research Publishing (SCIRP) is one of the largest Open Access journal publishers. It is currently publishing more than 200 open access, online, peer-reviewed journals covering a wide range of academic disciplines. SCIRP serves the worldwide academic communities and contributes to the progress and application of science with its publication.

Other selected journals from SCIRP are listed as below. Submit your manuscript to us via either submit@scirp.org or Online Submission Portal.
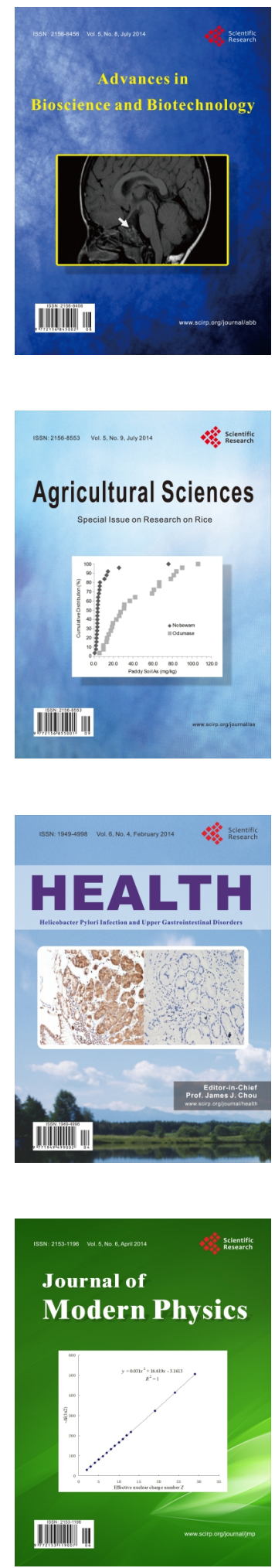
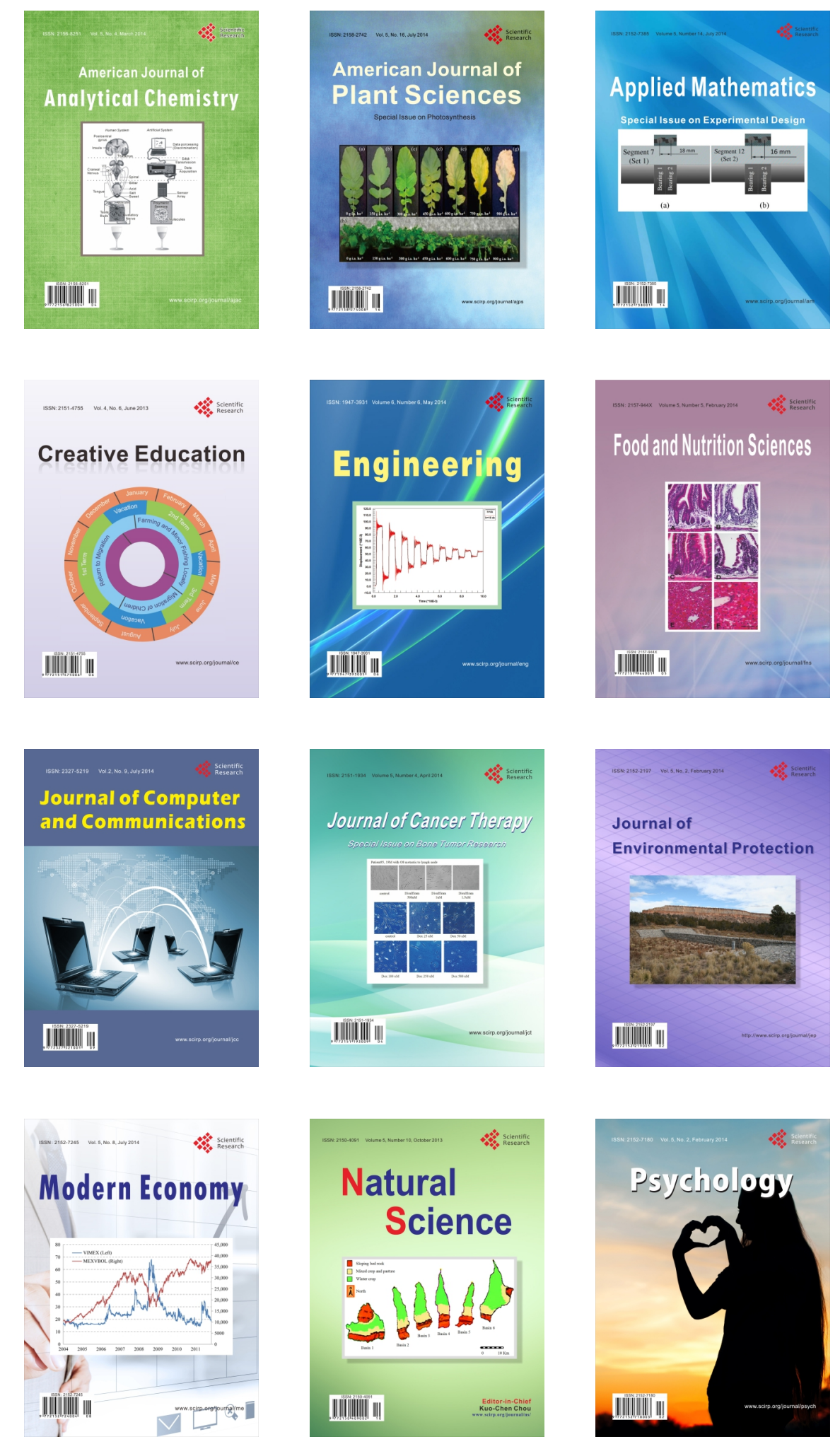